\title{
GPPS-CH-2020-0099
}

\section{HEAT RELEASE OF FUEL CELL POWERED AIRCRAFT}

\author{
Dragan Kožulović \\ Hamburg University of Applied Sciences \\ dragan.kozulovic@haw-hamburg.de \\ Hamburg, Germany
}

\begin{abstract}
Using a hydrogen fuel cell as primary power supply for the aircraft propulsion system, the heat dumping poses a large challenge, since the generated heat transfer rate is of the same magnitude as the electric power generated. An appropriate liquid cooling system and corresponding heat exchanger are sized in a preliminary manner and their impact at the aircraft performance is assessed, among others the additional power demand and weight, but in particular the additional drag of the heat exchanger. These results can be considered as first order estimations. It is found that the propulsive power demand of a mid-size commercial aircraft is increased by $27.3 \%$ at cruise flight by installing a suitable heat exchanger. Corresponding dimensions are sized and favourable parameters of the heat exchanger are estimated. For example, best performance is achieved if the inlet velocity to the heat exchanger is reduced to $15 \%$ of the flight velocity, the diameter based Reynolds number of the heat transferring tubes is 3100 , the length of the tubes is $0.217 \mathrm{~m}$ and the frontal area is $84 \%$ of the fuselage cross section. Due to large frontal area, the integration of the heat exchanger has been identified as a demanding task with considerable impact at the additional drag.
\end{abstract}

\section{INTRODUCTION}

The application of hydrogen fuel cell as primary aircraft power supply is one of the emerging opportunities to considerably reduce or completely prevent the $\mathrm{CO}_{2}$ emissions locally. This approach faces a lot of challenges (safety, energy density, electric motors, etc.) which have been or still are addressed in corresponding research programs. Given the very large heat generation, which is of comparable magnitude as the generated electric power, the heat dumping becomes also an enabling technology, if the fuel cell is intended to power mid- or large-size commercial aircraft flying at high subsonic velocities. Up to now, fuel cells have only been applied as primary power supply on small low-speed aircraft or as power source for aircraft subsystems, e.g. replacement of auxiliary power unit or wheel propulsion for taxiing purposes. The power demand in these applications is lower than $500 \mathrm{~kW}$, making the heat dumping a difficult but realizable engineering task.

Mid-size commercial airliners have a propulsive power demand of ca. $10 \mathrm{MW}$ at cruise and twice as much at take-off. There are already approaches to develop suitable fuel cells, e.g. (Kadyk et al., 2018), (Becker et al., 2018) and (Lück et al., 2019), however to the author's knowledge there is no publication addressing the airborne heat dumping at such large magnitudes. Hence the present work intends to provide first preliminary results on this issue.

Aircraft heat exchangers of $\mathcal{O}(\dot{Q}=100 \mathrm{~kW})$ are already widely used for cabin air conditioning and engine oil cooling, cf. (Carozza, 2017), (Wright et al., 2018) and (Vargas and Bejan, 2001). As demonstrated by (Kellermann et al., 2019) heat transfer rates of few MW can be achieved under favourable conditions and using the complete aircraft surface. To enable the operation also at non-favourable conditions and heat rates up to $20 \mathrm{MW}$, an extra heat exchanger is pursued in this work. Cooling the aircraft piston engines has also been conducted by extra heat exchangers, cf. (Hoerner, 1965) and (Drela, 1996), but at much smaller heat rates.

Heat exchangers of jet engines with intercooling and recuperation, among others investigated by (Kwan et al., 2011), (Misirlis et al., 2017) and (Gonser, 2008), operate at large heat transfer rates of several MW, as well as precoolers of air-breathing engines for hypersonic flight, $\mathrm{cf}$. (Varvill, 2008) and (Nacke et al. 2011). However, they operate at much larger temperatures, densities and temperature differences, hence the technology transfer to fuel cell cooling is not straight forward.

\section{METHODOLOGY}

As investigation vehicle, an aircraft of the similar size, weight and capacity as Airbus A320neo or Boeing B737MAX is selected. It is supposed that the gas turbine has been completely replaced by an electrically driven 
ducted propulsor (fan) together with power supplied by an installed fuel cell. Initially, the heat exchanger is not installed on this aircraft. The sizing and estimation of the heat exchanger is conducted in a preliminary manner as described below.

\section{Fuel Cell}

The power is supplied by a hydrogen protonexchange membrane fuel cell (PEMFC), which has been selected due to high power density of ca. $1 \mathrm{~kW} / \mathrm{kg}$ on the stack level (Beckhaus, 2019), significant improvement potential and operational flexibility due to relatively small reaction temperatures of ca. $100^{\circ} \mathrm{C}$. Typical characteristics of a PEMFC are shown qualitatively in Figure 1. The curves of generated power and heat may vary slightly, since they also depend on other parameters besides the current density, but in general they are very well approximated by the presented figure. This indicates that compact (and lightweight) fuel cell designs are best achieved at high current densities $i$, since maximum electric power $P_{e l, \max }$ is delivered at minimum membrane surface. However, in this case the fuel cell generates a heat transfer rate which is roughly twice as large as the generated power:

$$
\dot{Q} \approx 2 P_{e l} \text { at } P_{e l, m a x} \text { and high } i
$$

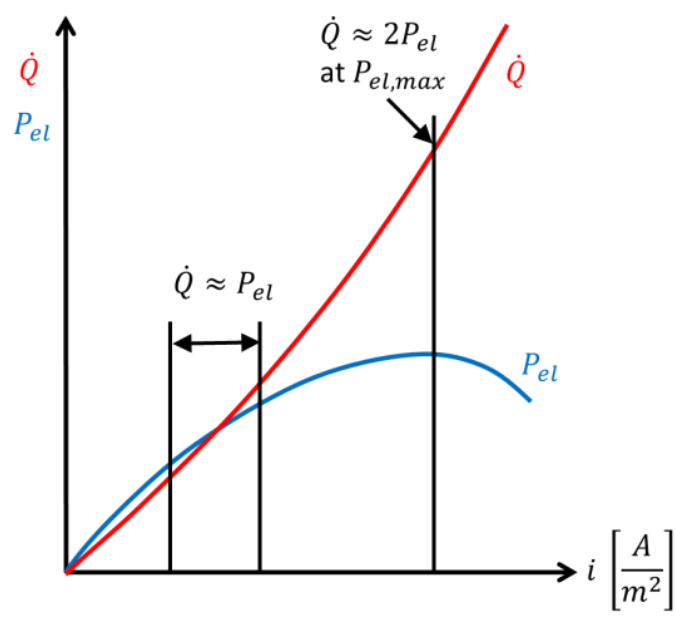

Figure 1: Sketch of generated electric power and heat transfer rate of hydrogen PEMFC after (Baehr and Kabelac, 2016) p. 516

Since the propulsive power of the investigated commercial aircraft is $9.3 \mathrm{MW}$, dumping double the amount of heat to the surrounding leads to excessive heat exchanger mass and friction. For this reason, moderate current densities, where the generated heat rate approximately equals the generated electric power is selected:

$$
\dot{Q} \approx P_{e l} \text { at moderate } i
$$

In this way, the larger weight of the fuel cell is overcompensated by the smaller weight and drag of the heat exchanger. Further, the fuel consumption is reduced since a smaller amount of stored hydrogen energy is converted into heat during the chemical reaction, that means the fuel cell efficiency is better.

\section{Power Demand}

Following the force equilibrium during the cruise flight, the propulsive power demand of the aircraft $P_{A C}$ is determined using the weight $W$ together with the $L / D$ ratio:

$$
\begin{gathered}
W=m_{A C} g \\
F=D=\frac{W}{\frac{L}{D}} \quad \text { with } \frac{L}{D}=20 \\
P_{A C}=F V_{0}
\end{gathered}
$$

This power demand refers only to the aircraft containing the fuel cell, cabling, electric motors and propulsors, but does not include the power associated with the heat dumping. This is taken into account in the overall power demand, which is to be determined:

$$
P_{\text {all }}=P_{A C}+P_{\text {heat }}
$$

Besides $P_{A C}$, which is considered as constant for given aircraft and flight conditions, additional power $P_{\text {heat }}$ has to be supplied by the fuel cell due to the installation of an extra heat exchanger, consisting of 3 parts:

$$
P_{\text {heat }}=P_{\text {core }}+P_{\text {ext }}+P_{\text {mass }}
$$

These parts represent three different additional drags (core $=$ internal flow through the heat exchanger; $e x t=$ external drag of the heat exchanger nacelle; mass $=\mathrm{drag}$ due to additional mass of the heat exchanger) which have to be compensated by corresponding thrust increase and are hence computed as follows:

$$
P_{\text {part }}=D_{\text {part }} V_{0}
$$

Following the assumption of equal heat and power generation of the fuel cell, Eq. (2), the overall heat transfer rate to be rejected equals the overall power:

$$
\dot{Q}_{a l l}=P_{\text {all }}
$$

Since the overall power and heat dumping demand is unknown a-priori, the computation is conducted in an iterative manner, cf. Figure 2. First, the heat exchanger is sized with $\dot{Q}_{a l l, 1}=P_{A C}$, which results in $P_{a l l, 1}$. Subsequently, the heat transfer rate is changed to $\dot{Q}_{a l l, 2}=$ $P_{a l l, 1}$ and the computation is repeated until $\dot{Q}_{a l l, N}=$ $P_{a l l, N-1}$. Obviously, the final heat exchanger size is larger than the size computed in the first iteration, since $\dot{Q}_{\text {all,final }}>P_{A C}$. Although this effect is captured by the iterative design of the heat exchanger, the quantification of additional power demand is only of first order accuracy, since the aircraft and the corresponding engine have not been changed. To achieve higher accuracy, the complete aircraft and the flight mission have to be redesigned. Although not conducted in this study, such aircraft-level investigation would likely lead to even more power demand (or some other penalty, e.g. reduced range). However, it is also likely that the higher order 
penalties are smaller than the first order penalty estimated in the present study.

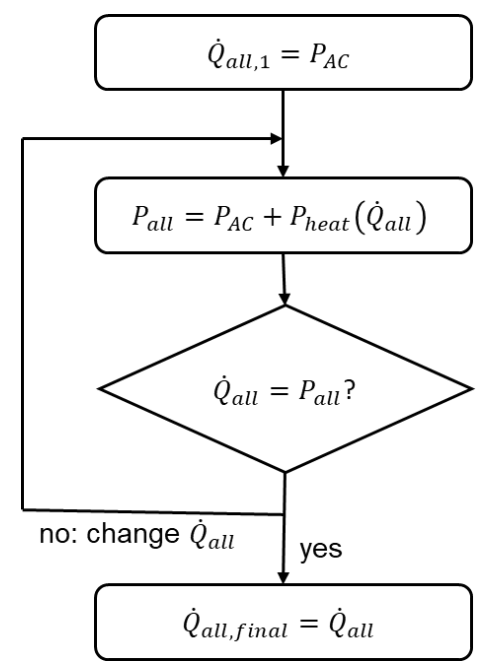

Figure 2: Iteration flowchart

The power demand for the coolant pump has been neglected, since the corresponding estimations yield comparatively small values of only a few hundreds of watts.

\section{Core Drag}

To determine the core drag $D_{\text {core }}$ and the corresponding drag power $P_{\text {core }}=D_{\text {core }} V_{0}$, the internal flow through the heat exchanger is computed step by step at the stations $0 \rightarrow 3$, as shown in Figure 3. Applying the momentum theorem to the internal flow (excluding the cowling drag, which is accounted for as external drag in the next section), together with the assumption of ideal expansion $p_{3}=p_{0}$ leads to:

$$
D_{\text {core }}=\dot{m}_{\text {core }}\left(V_{3}-V_{0}\right)
$$

To achieve the ideal expansion and to adapt the internal mass flow according to different flight conditions, a nozzle with variable flap is needed.

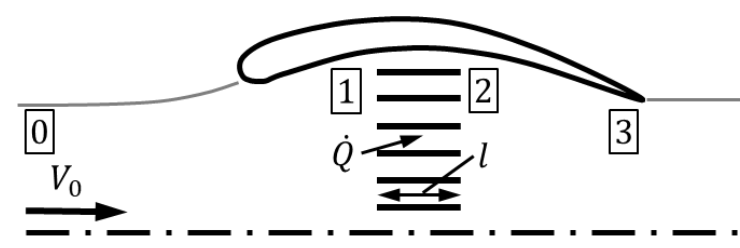

\section{Figure 3: Heat exchanger geometry and flow}

Table 1 shows the total pressure and total temperature ratios applied to the diffuser and nozzle. The diffuser pressure ratio translates to $4 \%$ total pressure loss, which is rather a large loss, in particular for cruise conditions, cf. (Bräunling, 2015, page 963 for the diffuser, page 1392 for the nozzle). This is justified by very strong diffusion, that means small ratios of $V_{1} / V_{0}$ (between 0.1 and 0.25 ), which is required in order to keep the friction loss inside the heat exchanger small. The corresponding computation of the heat exchanger (station $1 \rightarrow$ station 2 ) is explained in detail further below.

\begin{tabular}{|l|l|l|}
\hline Component & $\boldsymbol{\pi}$ & $\boldsymbol{\tau}$ \\
\hline Diffuser $(\mathbf{0} \rightarrow \mathbf{1})$ & 0.96 & 1.0 \\
\hline Nozzle $(\mathbf{2} \rightarrow \mathbf{3})$ & 0.99 & 1.0 \\
\hline
\end{tabular}

\section{Table 1. Total pressure and total temperature} ratios of the diffusor and the nozzle

Essentially, this type of heat exchanger is a ramjet engine, since the heat transfer leads to enthalpy increase of the internal massflow, which in turn is partially transferred to propulsive power. This mechanism only leads to positive overall thrust (or negative drag) if the flow loss inside the heat exchanger (including the diffuser and the nozzle) is very small, a condition which is rarely fulfilled for the present heat transfer problem. The ramjet effect is always present and always beneficial, although being usually smaller than the detrimental flow loss effect. The aforementioned calculation takes the ramjet effect into account, but in a mixed manner together with other effects. Isolating this effect for analysis purposes may be cumbersome, hence a theoretical power saving has been calculated by an isobaric temperature increase of the captured free stream by the same amount as in the heat exchanger. In this way, the flow is accelerated following the compressible flow relations. This theoretical case corresponds to an inviscid ramjet with constant static and total pressures throughout the engine, cf. (Hill and Peterson, 1992), pp. 155-164.

It is worth to mention that all calculations have been done by treating air as a perfect gas, that means with constant isobaric heat capacity $c_{p}=1005 \mathrm{~J} /(\mathrm{kg} \mathrm{K})$, constant heat capacity ratio $\gamma=1.4$ and temperature dependant viscosity by Sutherland's law.

\section{External Drag}

The cowling or the nacelle of the heat exchanger is an additional source of drag, which highly depends on the heat exchanger size and the integration. A wide variation of drag estimation can be found in the literature, a good overview is given by (Hoerner, 1965), chapter 9. Acceptable solutions can be found for different types of installations: fuselage-integrated, wing-integrated and wing-mounted. Due to relatively large heat exchanger dimensions, the latter type is preferred here. If the installation is positioned close to the wing trailing edge, following drag coefficient based on frontal area $A_{\text {front }}$ is provided by (Hoerner, 1965):

$$
c_{D}=\frac{D_{\text {ext }}}{\frac{\rho}{2} V_{0}^{2} A_{\text {front }}}=0.06
$$

In the present context, the frontal area is best approximated by the cross section at station $1, A_{\text {front }} \approx$ $A_{1}$. Obviously, minimizing this frontal area is one of the main objectives in the heat exchanger design.

As already mentioned, the estimation of the external drag is very difficult on this preliminary level, since suitable and synergetic integrations may considerably reduce the drag. For example, a very beneficial wingintegrated configuration has been developed by (Drela, 
1996), among others by recovering the wing boundary layer by the released heat. In contrast, the compressibility effects at high subsonic velocities may also lead to rapid increase of the drag coefficient, as demonstrated for jet engine nacelles by (Heidebrecht and MacManus, 2019).

Overall, it is felt by the author that the external drag estimation was the element with the largest uncertainty in the current study, an issue which has to be addressed much more intensely in the future.

\section{Mass Drag}

The additional drag by heat exchanger weight is determined analogous to the drag of the overall aircraft weight via $L / D$-ratio:

$$
D_{\text {mass }}=\frac{m_{H E} g}{\frac{L}{D}}
$$

In this equation, $m_{H E}$ containes the material mass of the heat exchanger and the coolant mass together with a sizing factor of 1.2 to account for coolant pipes and pumps, as well as for the cowling:

$$
m_{H E}=1.2\left[m_{A l}+\left(2 m_{H 2 O}\right)\right]
$$

Aluminium has been selected as heat exchanger material, due to its large thermal conductivity of $\lambda_{A l}=$ $220 \mathrm{~W} /(\mathrm{m} \mathrm{K})$ and low density of $\rho_{A l}=2710 \mathrm{~kg} / \mathrm{m}^{3}$. Although copper has a better thermal conductivity, it is not suitable due to much larger density. Thus, it is not surprising that Aluminium is mostly applied for mobile heat exchangers, especially in aviation. As will be explained in detail later, the heat transfer is conducted in tubular elements of triangular cross section for the air and rectangular cross section for the coolant. The wall thickness has been kept constant throughout the study to a value of $t_{A l}=0.2 \mathrm{~mm}$. Sizing the heat exchanger length and number of tubes allows for a simple calculation of solid heat exchanger mass.

Water has been selected as coolant and the corresponding mass inside the heat exchanger has been calculated in the same manner, this time using the rectangular cross section. Assuming that roughly the same amount of coolant has to be used in the fuel cell stack, the water mass has been doubled.

For higher heat transfer efficiency, the direct cooling of the fuel cell stack by the ram air is the superior concept. However, this concept has been skipped in favour of intermediate liquid coolant, since it enables a much more homogeneous heat removal from the fuel cell stack and prevents foreign object contamination of this very sensitive component.

\section{Heat Exchanger}

The counter-flow liquid-air heat exchanger has been selected due to its compact dimensions. As shown in Figure 4, corrugated metal fins are used, which are sinusoidal in practice, but for simplicity have been assumed as straight fins sloped by $45^{\circ}$. In this way, long tubes of triangular cross section are shaped for the air flow. The Reynolds number and the corresponding hydraulic diameter are:

$$
\begin{aligned}
& R e_{d}=\frac{V_{b} \rho_{b} d_{h}}{\mu} \\
& d_{h}=\frac{h_{\text {pass }}^{2}}{e}
\end{aligned}
$$

with perimeter $e=2(1+\sqrt{2}) h_{\text {pass }}$
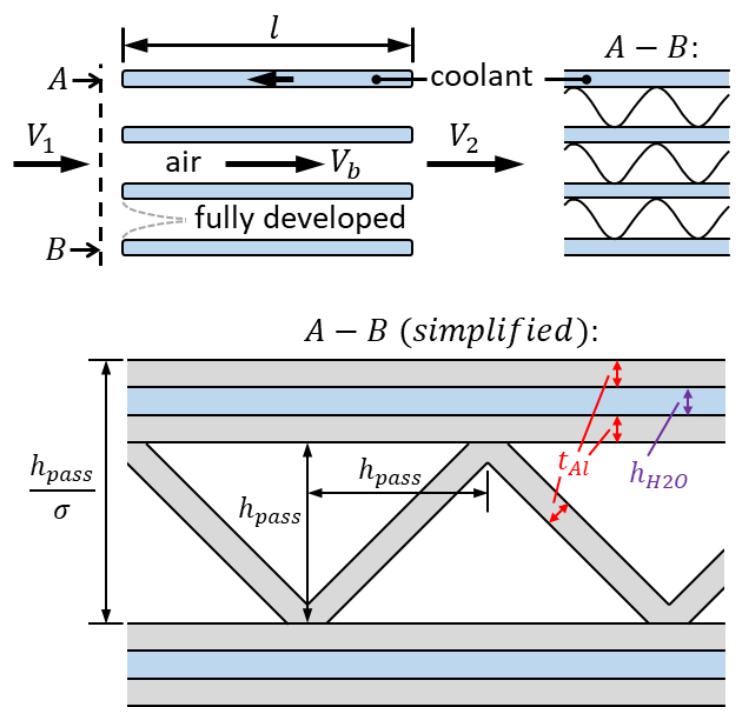

Figure 4: Heat exchanger configuration

For $R e_{d}<2300$ laminar correlations for smooth walls have been used, otherwise the turbulent ones, according to (Kays and Crawford, 1987), chap. 8 and 13:

$$
\begin{aligned}
\text { Laminar: } \quad c_{f}=\frac{16}{R e_{d}} & N u=3.0 \text { (triangular) } \\
\text { Turbulent: } c_{f}=\frac{0.078}{\sqrt[4]{R e_{d}}} & N u=0.022 \sqrt{P r} R e_{d}^{0.8} \\
\text { In both cases: } & S t=\frac{N u}{P r \cdot R e_{d}}
\end{aligned}
$$

The correlations correspond to the case of constant heat flux, which is fulfilled by requiring the same fluid capacity rates in a counter-flow heat exchanger. Together with the perfect gas assumption, this leads to constant local temperature difference $\Delta T_{l o c}$ along the tube, as shown in Figure 5. On the inlet/outlet level, the temperatures of both the air and the coolant are changed by $\Delta T_{\text {fluid }}$. Together, both temperature differences comprise the overall temperature difference $\Delta T_{\text {all }}$, which represents the overall potential for the heat transfer:

$$
\Delta T_{\text {all }}=\Delta T_{\text {loc }}+\Delta T_{\text {fluid }}(20)
$$

Since the fuel cell reaction takes place at ca. $100^{\circ} \mathrm{C}$, the coolant temperature supplied to the heat exchanger is assumed to be $80^{\circ} \mathrm{C}$. The air temperature entering the heat exchanger depends on the altitude and flight Mach number. Typical value for the cruise conditions at $11 \mathrm{~km}$ and $M_{0}=0.8$ is $-29^{\circ} \mathrm{C}$, resulting in $\Delta T_{\text {all }}=109 \mathrm{~K}$. Splitting the overall heat transfer potential into the local and fluid temperature difference is governed by the 
following parameter, which has also been varied in this study:

$$
F_{T, \text { split }}=\frac{\Delta T_{\text {fluid }}}{\Delta T_{\text {all }}}
$$

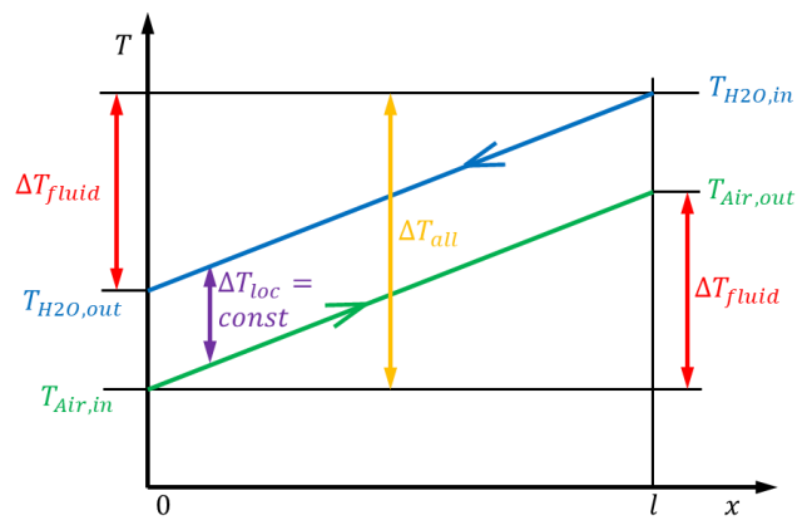

\section{Figure 5: Temperature distribution in counter-flow heat exchanger with equal fluid capacity rates}

As the air moves from station 1 into the heat exchanger passage, the cross section is reduced and the velocity is increased to $V_{b, \text { in }}$, which is accounted for by the displacement factor $\sigma$ :

$$
\begin{gathered}
V_{b, i n}=\frac{\mathrm{V}_{1}}{\sigma} \\
\sigma=\frac{h_{\text {pass }}}{h_{\text {pass }}+h_{H 2 O}+2 t_{A l}}
\end{gathered}
$$

The coolant passage height and the aluminium wall thickness are both kept constant to $0.2 \mathrm{~mm}$ and the air passage height $h_{\text {pass }}$ has been varied. The displacement factor $\sigma$ results in a typical range between 0.7 and 0.9 . The bulk velocity $V_{b, i n}$ is further accelerated by heat transfer to $V_{b, o u t}$, which is also accounted for in the calculations. An arithmetic mean value of the bulk velocity has been used for the computation of the Reynolds number in Eq. (14) and the flow losses:

$$
\Delta p_{\text {loss }}=2 c_{f} V_{b}^{2} \frac{l}{d_{h}} \rho
$$

Water, which has been selected as coolant, flows in the opposite direction through a rectangular cross section with a constant height of $0.2 \mathrm{~mm}$ and width of $1.6 \mathrm{~mm}$, resulting in a large side ratio of 8 . According to (Kays and Crawford, 1987), the Nusselt number for the laminar flow through this section is 6.49. In all investigated cases, the water flow Reynolds number, again based on the hydraulic diameter of its own rectangular cross section, was well below the critical value of 2300 , thus the use of laminar correlations. Water properties may vary considerably with temperature. Here, they have been assumed constant at a mean temperature of $40^{\circ} \mathrm{C}$, which is suitable for the cruise conditions as investigated in the next chapter:

$$
\operatorname{Pr}=4.5 \quad \rho=1000 \frac{\mathrm{kg}}{\mathrm{m}^{3}} \quad c_{p}=4182 \frac{\mathrm{J}}{\mathrm{kg} \mathrm{K}}
$$

$$
\mu=6 \cdot 10^{-4} \mathrm{PaS} \quad \lambda=0.63 \frac{\mathrm{W}}{\mathrm{mK}}
$$

The heat transfer coefficient is combined as follows (fouling is neglected):

$$
\begin{array}{r}
\alpha=\left(\frac{1}{\alpha_{H 2 O}}+\frac{t_{A l}}{\lambda_{A l}}+\frac{1}{\alpha_{A i r}}\right)^{-1} \\
\alpha_{A i r}=S t V_{b} \rho_{b} c_{p} \quad \alpha_{H 2 O}=\frac{N u \lambda_{H 2}}{d_{h, H 2 O}}
\end{array}
$$

Typically, $\alpha_{\text {Air }}$ is much smaller than the other coefficients, hence it dominates the overall coefficient. Further, according to the fin dimensions and the thermal conductivity of aluminium, the sloped fins transfer the heat almost as good as the water containment walls.

Finally, the length of the heat exchanger is determined:

$$
l=F_{\text {size }} \frac{c_{p} \dot{m}_{\text {tube }}}{e \alpha} \frac{\Delta T_{\text {fluid }}}{\Delta T_{\text {loc }}}
$$

The factor $F_{\text {size }}=1.2$ makes sure that the length is oversized by $20 \%$ to account for simplifying assumptions and the drag produced by the entry and exit regions of the heat exchanger. Further, the heat exchanger length was at least 2 or 3 times larger than the entry length for fully developed tube flow. Hence, the influence of increased skin friction and heat transfer in the entry region is rather small.

The number of tubes for dumping the complete heat transfer rate is found by:

$$
n_{\text {tube }}=\frac{\dot{Q}_{\text {all }}}{\dot{Q}_{\text {tube }}}=\frac{\dot{Q}_{\text {all }}}{c_{p} \dot{m}_{\text {tube }} \Delta T_{\text {fluid }}}
$$

The corresponding cross sections are:

$$
\begin{gathered}
A_{\text {pass }}=n_{\text {tube }} h_{\text {pass }}^{2} \\
A_{1}=\frac{A_{\text {pass }}}{\sigma}
\end{gathered}
$$

\section{RESULTS AND DISCUSSION}

\section{Reference Configuration}

The parameters of the reference aircraft and heat exchanger configuration are given in Table 1. These values represent the optimum combination. The cruise conditions and the aircraft mass correspond to today's A320neo or B737MAX, whereas the lift-to-drag ratio is somewhat larger, to account for technological improvement of the next aircraft generation. According to Eq. (6), the propulsive power for this aircraft is increased from $9.27 \mathrm{MW}$ to $11.46 \mathrm{MW}$, or by $23.7 \%$. This increase refers to the aircraft with installed engines, electric motors and fuel cells. The amount is more than significant, but it can be judged as moderate when related to the massive amount of dumped heat. Another remarkable result is the rather small contribution of the core drag power $P_{\text {core }}$ to this increase $(5.3 \%)$. This can be explained by the ramjet effect, which recovers $13.2 \%$ of the drag power generated by the core flow. In other words, the ramjet effect compensates $71 \%$ of the core drag power. Further, the 
power demand by additional mass is rather small (2\%), whereas the main increase stems from the external drag $(16.4 \%)$. As discussed in the method section, the latter result is not very reliable. The heat exchanger frontal area $A_{1}$ equals $84 \%$ of the fuselage cross section (fuselage diameter of $4 \mathrm{~m}$ ), which is similar to the frontal area of the both engines. Hence a large-scale integration of the heat exchanger is necessary, which may shift the external drag contribution in both directions significantly.

\begin{tabular}{|c|c|}
\hline \multicolumn{2}{|c|}{ Flight conditions - cruise } \\
\hline altitude & $11 \mathrm{~km}$ \\
\hline$M_{0}$ & 0.8 \\
\hline$p_{0}$ & $22700 \mathrm{~Pa}$ \\
\hline$T_{0}$ & $216.77 \mathrm{~K}=-56.38^{\circ} \mathrm{C}$ \\
\hline$m$ & $80000 \mathrm{~kg}$ \\
\hline$L / D$ & 20 \\
\hline \multicolumn{2}{|l|}{ Powers } \\
\hline$P_{A C}$ & $9.27 \mathrm{MW}$ \\
\hline$P_{\text {all }}=\dot{Q}_{\text {all }}$ & $11.46 M W=1.237 P_{A C}$ \\
\hline$P_{\text {core }}$ & $0.492 M W=0.053 P_{A C}$ \\
\hline$P_{\text {mass }}$ & $0.183 M W=0.020 P_{A C}$ \\
\hline$P_{\text {ext }}$ & $1.521 M W=0.164 P_{A C}$ \\
\hline$P_{\text {ram }}$ & $-1.223 M W=-0.132 P_{A C}$ \\
\hline \multicolumn{2}{|c|}{ Heat exchanger } \\
\hline$V_{1} / V_{0}$ & 0.15 \\
\hline$F_{T, \text { split }}$ & 0.6 \\
\hline$R e_{d}$ & 3120 (turbulent) \\
\hline$h_{\text {pass }}$ & $3.05 \mathrm{~mm}$ \\
\hline$\sigma$ & 0.776 \\
\hline$\pi_{H E}$ & 0.936 \\
\hline$l$ & $0.217 \mathrm{~m}$ \\
\hline$n_{\text {tube }}$ & 880115 \\
\hline$\alpha$ & $112 W /\left(m^{2} K\right)$ \\
\hline$\dot{m}_{\text {core }}$ & $174 \mathrm{~kg} / \mathrm{s}$ \\
\hline$A_{1}$ & $10.56 m^{2} \equiv 0.84 A_{F L}$ \\
\hline$A_{H T}$ & $2348 \mathrm{~m}^{2}$ \\
\hline$A_{H T} / V_{H E}$ & $1023 \mathrm{~m}^{2} / \mathrm{m}^{3}$ \\
\hline \multicolumn{2}{|l|}{ Masses } \\
\hline$m_{A l}$ & $1080 \mathrm{~kg}$ \\
\hline$m_{\mathrm{H} 2 \mathrm{O}}$ & $116.7 \mathrm{~kg}$ \\
\hline$m_{H E}$ & $1576 \mathrm{~kg}$ \\
\hline
\end{tabular}

Table 2: Parameters of the reference configuration

The velocity ratio $V_{1} / V_{0}$ is set to a small value of 0.15 , in order to keep the flow loss small and the total pressure ratio large, in this case $\pi_{H E}=0.936$. Further, the temperature splitting factor is set to 0.6 , that means the temperature of both fluids is changed by $60 \%$ of the maximum temperature difference when they leave the heat exchanger, whereas $40 \%$ are left for the local heat transfer inside the tubes. The Reynolds number indicates the beginning of the turbulent flow regime. The length of the heat exchanger is rather small $(0.217 \mathrm{~m})$, especially when compared to the frontal area, which requires a few meters for the width and the height. This is not surprising, since the disposable temperature difference is only ca. $100 \mathrm{~K}$, and it takes only a short tube length to heat up the air by this magnitude. Hence, many parallel short tubes are necessary to reject the large heat amount, $n_{\text {tube }}=$ $\mathcal{O}\left(10^{6}\right)$. A heat exchanger is denoted as "compact" and suitable for aircraft applications if it's ratio of heat transfer area to the overall volume $A_{H T} / V_{H E}$ exceeds $700 \mathrm{~m}^{2} / \mathrm{m}^{3}$, cf. Shah and Sekulić (2003) page 8, a criterion which is clearly fulfilled by the present device. The major part of the heat exchanger mass stems from the aluminium walls and fins.

\section{Sensitivities}

To find the dominant parameters for the present heat transfer problem, several variations have been conducted. First, the Reynolds number of the tube flow has been varied by the passage height $h_{\text {pass }}$. As can be seen in Figure 6, the power demand is largest at small Reynolds numbers, where the tube flow is laminar, $R e_{d}<2300$. This power demand is strongly decreased with increasing Reynolds number, especially when crossing the critical Reynolds number and the tube flow becomes turbulent. For $R e_{d}>3000$, a still a small decrease can be observed, which levels off at even larger Reynolds numbers. In the turbulent regime, the external drag contribution remains almost constant, while the core and mass drag contributions switch their roles. It is well known that large Reynolds numbers decrease the friction coefficient and thus the core power. On the other hand, this benefit is compensated by increased heat exchanger mass. This mass increase is driven by longer tubes, while the cross section $A_{1}$ remains almost constant. Since the smallest investigated turbulent Reynolds number $R e_{d}=3100$ yields the lowest heat exchanger weight, it has been selected as reference parameter, even if the overall power demand is a little bit smaller at larger Reynolds numbers.

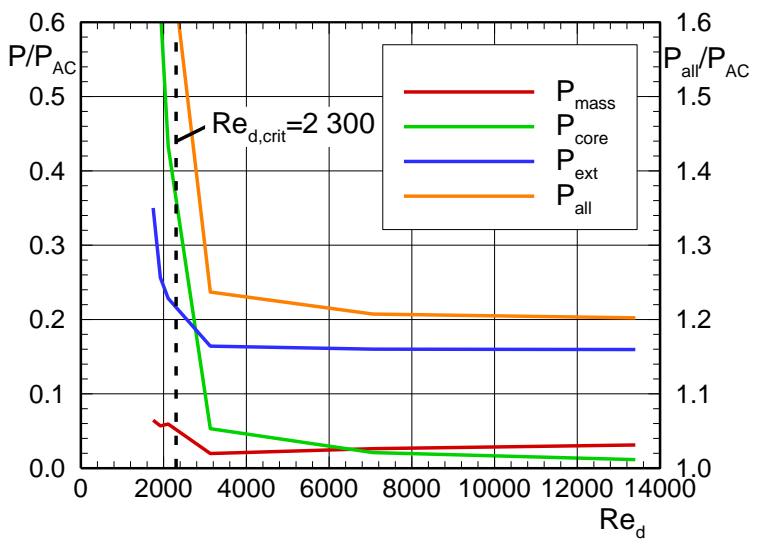

Figure 6: Influence of tube Reynolds number 
The explanation for the considerably improved performance of the turbulent tube flow is found in the following equation, which has been derived by (Drela, 1996) for a similar problem (constant wall temperature):

$$
P_{\text {core }}=\dot{Q}\left[\frac{V_{0}^{2}}{2 c_{p}\left(T_{H E}-T_{1}\right)} \frac{1}{\sigma} \frac{c_{f}}{S t}\left(\frac{V_{1}}{V_{0}}\right)^{2}-\frac{\gamma-1}{2} M_{0}^{2}\right]
$$

Some simplifying assumptions have been made by Drela, but the equation still captures the main mechanisms. The first term in the bracket represents the drag producing mechanisms and the second the ramjet effect. It is revealed that the ratio $c_{f} / S t$ has to be minimized if the core drag power is to be reduced. This value changes from 3.84 in the laminar flow to ca. 1.95 in the turbulent flow, which almost cuts the drag power by half. Hence, the recommendation is to design the heat exchanger at minimum $c_{f} / S t$-ratio. In the present case of counter-flow heat exchanger (constant heat flux), this is best achieved by turbulent tube flow. In contrast, in the case of constant wall temperature the flow is preferably kept laminar and the tube length should be limited to the length of the entry region, since the fully developed downstream flow only produces losses at very small heat exchange rates, due to adaption of the fluid temperature to the wall temperature, cf. (Drela, 1996).

In general, there are many passive and active methods to influence the skin friction and heat transfer, among others by roughness, pin fins, dimple arrays, twisted tapes and many others. Usually, if the heat transfer is increased, the skin friction is increased also. Hence, any method which enhances heat transfer more than skin friction is suitable for the present heat transfer problem, since the $c_{f} / S t$-ratio is reduced, cf. (Ligrani, 2006), (Dewan, 2004), (Sonowane, 2016) and (Maradiya, 2018).

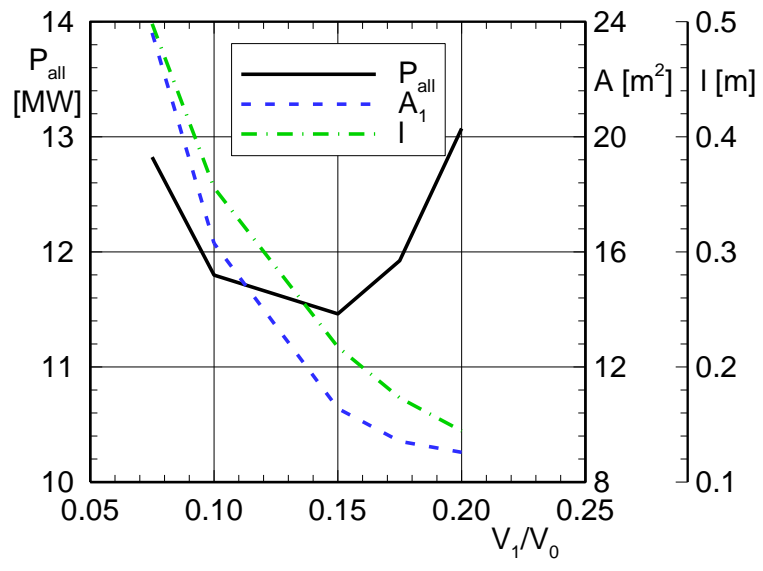

Figure 7: Influence of velocity ratio

Another parameter of large influence in Eq. (31) is the velocity ratio $V_{1} / V_{0}$, which is even squared when applied to the drag power. Consequently, a rapid increase is also reflected by the present method for $V_{1} / V_{0}>0.15$, cf. Figure 7. This underlines the need to strongly decelerate to flow prior to the heat transfer. However, even smaller $V_{1} / V_{0}$-values should not be set, since the drag power rises again. In this case, both the cross section $A_{1}$ and the length $l$ of the heat exchanger are large, giving rise to the corresponding drags.

The influence of the temperature splitting factor $F_{T, \text { split }}$ is displayed in Figure 8. The selected value of $F_{T, \text { split }}=0.6$ for the reference configuration is the optimum value. Lower values yield drag increase due to larger frontal surface and larger values due to longer tubes.

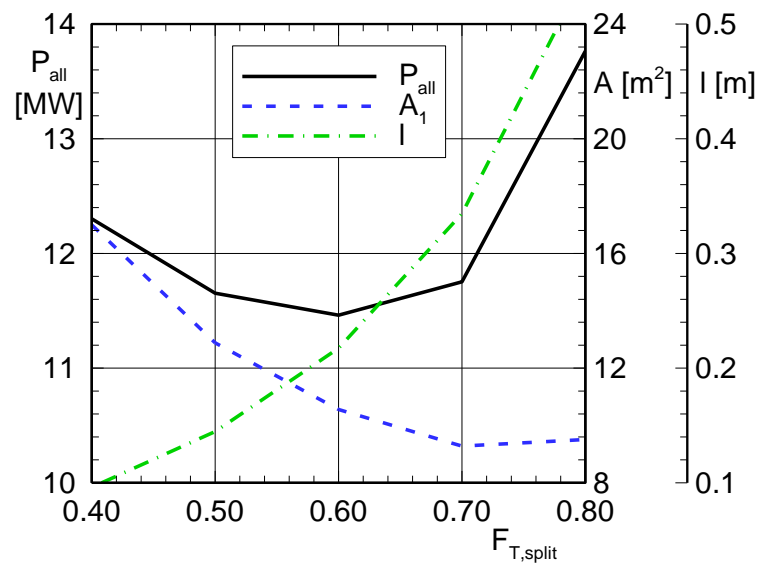

Figure 8: Influence of temperature splitting factor

Due to the linear relation between the aircraft power demand and the weight (via $L / D$-ratio), $P_{A C}$ increases directly proportional to the flight Mach number, but the additional power demand increases progressively, $\mathrm{cf}$. $P_{a l l} / P_{A C}$ in Figure 9. This non-linear increase stems from the external drag, which is coupled to the flight velocity by a square relation. The increase is probably even stronger, due to the transonic drag increase, which has not been captured here. Since $P_{A C}$ and $P_{\text {heat }}$ are reduced at smaller flight Mach numbers, it may be an attractive option to operate a fuel cell powered aircraft at somewhat reduced Mach numbers.

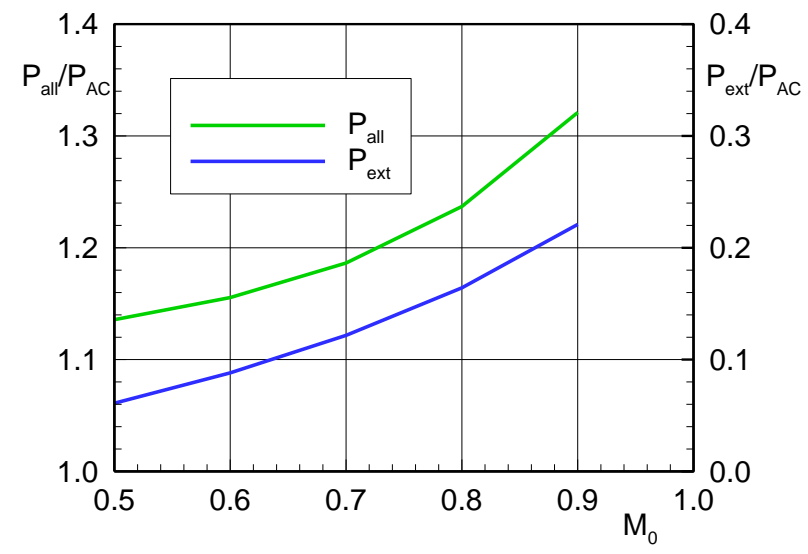

Figure 9: Influence of flight Mach number

To analyse the combined influence of flight Mach number and flight altitude, a configuration with $M_{0}=0.5$ 
and altitude of $5 \mathrm{~km}$ has been investigated. For this case, $P_{\text {all }} / P_{A C}$ was 1.288 , which poses a larger relative increase when compared to the reference case (1.237). Larger air density and larger temperature at lower altitude seem to counterbalance the effect of reduced flight velocity. Hence, cruising altitudes of conventional aircraft seem to be appropriate for the fuel cell powered aircraft.

As a final study, the heat exchanger performance has been assessed for the take-off condition $\left(M_{0}=0.25\right.$, altitude $\left.0 \mathrm{~km}, F_{\text {take-off }}=5 F_{\text {cruise }}\right)$. Additionally, the diffusor pressure recovery was increased from 0.96 to 0.99 , to account for lower diffusion losses at smaller velocities. Overall, a reasonable value of $P_{A C}=$ 16.69 MW is computed, which is 1.8 times larger than the aircraft power demand at cruise conditions. Interestingly, the heat-related drag power is only $P_{\text {heat }}=2.12 \mathrm{MW}$, resulting in $P_{\text {all }}=18.81 \mathrm{MW}$ or $P_{\text {all }} / P_{A C}=1.127$. Both the core and external drag are small, due to small flight velocity. Although the temperature difference is considerably smaller, the heat transfer efficiency is comparable to the cruise conditions, due to the large air density. Some heat exchanger parameters are kept to the same values as the cruise condition $\left(V_{1} / V_{0}, F_{T, s p l i t}, R e_{d}\right)$, but others have been modified ( $l$ from $0.217 \mathrm{~m}$ to 0.268 $\mathrm{m}$; $h_{\text {pass }}$ from $3.05 \mathrm{~mm}$ to $3.7 \mathrm{~mm}$ ). However, the modifications are rather moderate, rising hope that a multi-point design procedure can provide a heat exchanger suitable for both flight conditions. Of course, also the fuel cell has to be sized to the larger take-off power demand, or some hybrid propulsion concept with short-time boosting may be applied.

\section{CONCLUSIONS}

The heat releasing system of a fuel cell powered midrange commercial aircraft has been sized in a preliminary manner and first order estimations have been made to the additional propulsive power demand. Assuming that the heat transfer rate equals the electric power generated by the fuel cell, the installation of the corresponding heat exchanger leads to a considerable additional drag power. Three essential drag sources have been identified: core flow, external flow and heat exchanger mass. Main conclusions for the cruise conditions (altitude $11 \mathrm{~km}$, flight Mach number $M_{0}=0.8$ ) are:

1. Heat dumping leads to additional $23.7 \%$ propulsive power demand, which is composed of $16.4 \%$ external drag power, $5.3 \%$ core drag power and $2.0 \%$ drag power from the additional mass.

2. The core drag power is considerably reduced by the ramjet effect.

3. Due to the small disposable temperature difference, the length of the heat exchanger is rather small $(0.217$ $\mathrm{m})$ and the frontal area is large. The latter equals $84 \%$ of the fuselage cross section, which leads to the large contribution of the external drag to the additional power demand.

4. Turbulent tube flow with $R e_{d} \approx 3100$ has been identified as a suitable flow regime, due to small $c_{f} / S t$-ratio, that means low loss production at high heat transfer rates, and also due to small heat exchanger weight.

5. Velocity ratio of $V_{1} / V_{0}=0.15$ yields the lowest heat exchanger power demand.

Following results have been obtained for other conditions:

6. Reducing the flight Mach number leads to significant reduction of additional power demand, e.g. $6 \%$ at $M_{0}=0.5$.

7. Reducing the flight altitude to $5 \mathrm{~km}$ leads to similar additional power demand as cruise conditions.

8. Sizing the heat exchanger for the take-off conditions yields very similar parameters as for the cruise conditions.

Future work will focus at in-depth investigations of aircraft-level integration of the large heat exchanger system, together with heat transfer enhancement methods. Further, multi-point design of the heat exchanger is necessary, in order to qualify the fuel cell as the primary power source for the complete flight mission.

\begin{tabular}{ll} 
NOMENCLATURE \\
Latin Symbols \\
$b$ & bulk \\
$c_{f}$ & skin friction coefficient \\
$c_{p}$ & specific heat capacity at constant pressure \\
$D$ & drag \\
$e$ & perimeter \\
$e l$ & electric \\
$F$ & thrust \\
$F_{\text {size }}$ & sizing factor \\
$g$ & gravity acceleration, $9.81 \frac{\mathrm{m}}{\mathrm{s}}$ \\
$h$ & hydraulic \\
$i$ & current density \\
$L$ & lift \\
$M$ & Mach number \\
$m$ & mass \\
$N u$ & Nusselt number \\
$P$ & power \\
$p$ & pressure \\
$P r$ & Prandtl number \\
$\dot{Q}$ & heat transfer rate \\
$R e$ & Reynolds number \\
$S t$ & Stanton number \\
$T$ & temperature \\
$t$ & wall thickness \\
$V$ & velocity \\
$W$ & weight \\
\hline
\end{tabular}

\section{Greek Symbols}

$\alpha \quad$ heat transfer coefficient

$\gamma \quad$ heat capacity ratio (isobaric/isochoric)

$\lambda$ thermal conductivity

$\mu \quad$ dynamic viscosity

$\pi \quad$ total pressure ratio

$\rho$ density

$\sigma \quad$ displacement factor 


\section{Abbreviations}

$A C \quad$ aircraft

$F L \quad$ fuselage

$H E$ heat exchanger

$H T$ heat transfer

$P E M F C$ proton-exchange membrane fuel cell

\section{ACKNOWLEDGMENTS}

Several very fruitful discussions with following colleagues have considerably improved author's understanding and knowledge of fuel cell systems: Dr. Jutta Abulawi (HAW Hamburg), Dr. Peter Beckhaus (ZBT Duisburg), Niko Lehmann (Airbus Hamburg), Dr. Jens Friedrichs, Dr. Christoph Bode and Dr. Xin Gao (all from TU Braunschweig).

\section{REFERENCES}

Baehr, H. D. and Kabelac, S. (2016). ThermodynamikGrundlagen und technische Anwendungen. 16th ed., Berlin, Springer Vieweg.

Becker, F.; Gentner, C.; Montaner Rios, G.; Sokolov, I. and Kallo, J. (2018). Steigerung der Leistungsfähigkeit von Brennstoffzellensystemen für luftfahrttechnische Anwendungen. Proc. DLRK2018-480233

Beckhaus, P. (2019). Private Communication, Zentrum für Brennstoffzellentechnik, Duisburg, Germany

Bräunling, W. (2015). Flugzeugtriebwerke. 4. Auflage, Springer Vieweg, Berlin

Carozza, A. (2017). Heat Exchangers in the Aviation Engineering. Chapter in: Heat Exchangers - Advanced Features and Applications. Edited by Sohel Murshed, S. M. Intechopen.

Dewan, A.; Mahanta, P.; Sumithra Raju, K. and Suresh Kumar, P. (2004). Review of passive heat transfer augmentation techniques. Proc. Instn Mech. Engrs Vol. 218 Part A: J. Power and Energy

Drela, M. (1996). Aerodynamics of Heat Exchangers for High-Altitude Aircraft. J. Aircraft, 33(2), pp. 176-184.

Gonser, H. (2008). Untersuchungen zum Einsatz von Wärmetauschern in zivilen Turboflugtriebwerken. $\mathrm{PhD}$. Stuttgart University.

Heidebrecht, A. and MacManus, D.G. (2019) Surrogate model of complex non-linear data for preliminary nacelle design. Aerospace Science and Technology 84, pp. 399-411

Hill, P. and Peterson, C. (1992). Mechanics and Thermodynamics of Propulsion. $2^{\text {nd }}$ Ed. Pearson

Hoerner, S. F. (1965). Fluid-Dynamic Drag. Bakersfield (CA), published by the author.

Kadyk, T.; Winnefeld, C.; Hanke-Rauschenbach, R. and Krewer, U. (2018). Analysis and Design of Fuel Cell Systems for Aviation, Energies 2018, 11, 375
Kays, W. M. and Crawford, M. E. (1987). Convective Heat and Mass Transfer. 2nd ed., New York, McGrawHill.

Kellermann, H.; Habermann, A. L. and Hornung, M. (2019). Assessment of Aircraft Surface Heat Exchanger Potential. Aerospace 7(1)

Kwan, P.-W.; Gillespie, D. R. H.; Stieger, R. D. and Rolt, A. M. (2011). Minimising Loss in a Heat Exchanger Installation for an Intercooled Turbofan Engine. Proc. GT2011-45814

Ligrani, P. M. (2006). Dimple Array Effects on Turbulent Heat Transfer and Flow Structure. In: Turbulence, Heat and Mass Transfer 5. Edited by Hanjalic, K., Nagano, Y. and Jakirlic, S., Begell House.

Lück, S.; Wittmann, T.; Bode, C. and Friedrichs, J. (2019). Analysis of the impact of moist air in the gas path of air supply systems with energy recovery for fuel cell powered aircraft. Proc. DLRK2019-490173

Maradiya, C.; Vadher, J. and Agarwal, R. (2018). The heat transfer enhancement techniques and their Thermal Performance Factor. Beni-Suef University Journal of Basic and Applied Sciences, 7, pp. 1-21.

Misirlis, D.; Vlahostergios, Z.; Flouros, M.; Salpingidou, C.; Donnerhack, S. Goulas, A. and Yakinthos, K. (2017). Optimization of Heat Exchangers for Intercooled Recuperated Aero Engines. MDPI Aerospace, 4, 14

Nacke, R.; Northcutt, B. and Mudawar, I. (2011). Theory and experimental validation of cross-flow micro-channel heat exchanger module with reference to high Mach aircraft gas turbine engines. International Journal of Heat and Mass Transfer 54, pp. 1224-1235

Shah, R.K. and Sekulić, D.P. (2003). Fundamentals of Heat Exchanger Design. Hoboken (New Jersey), John Wiley \& Sons

Sonowane, T.; Patil, P.; Chavhan, A. and Dusane, B. M. (2016). A review of heat transfer enhancement by passive methods", International Research Journal of Engineering and Technology, 3(9), pp. 1567-1574

Van Wensveen, J.; Peter, F.; Rau, T. and Hornung, M. (2020). Assessment of a Fuel Cell Powered Full Electric Subsystem Architecture for the AVACON Research Baseline Aircraft. Proc. DLRK2019-490114

Vargas, J. V. C. and Bejan, A. (2001). Thermodynamic optimization of finned crossflow heat exchangers fore aircraft environmental control system. Int. J. of heat and Fluid Flow, 22, pp. 657-665

Varvill, R. (2008). Heat Exchanger Development at Reaction Engines Ltd. Proc. IAC-08-C4.5.2

Wright, S. J.; Dixon-Hardy, D. W. and Heggs, P.J. (2018). Aircraft air conditioning heat exchangers and atmospheric fouling. Thermal Science and Engineering Progress, 7, pp. 184-202 